University of Wollongong

Research Online

Faculty of Engineering and Information

Faculty of Engineering and Information

Sciences - Papers: Part A

Sciences

$1-1-2014$

\title{
Microstructure and mechanical properties of AA5005/AA6061 laminated composite processed by accumulative roll bonding
}

\author{
Lihong Su \\ University of Wollongong, lihongsu@uow.edu.au \\ Cheng Lu \\ University of Wollongong, chenglu@uow.edu.au \\ Guanyu Deng \\ University of Wollongong, gdeng@uow.edu.au
}

A Kiet Tieu

University of Wollongong, ktieu@uow.edu.au

Follow this and additional works at: https://ro.uow.edu.au/eispapers

Part of the Engineering Commons, and the Science and Technology Studies Commons 


\title{
Microstructure and mechanical properties of AA5005/AA6061 laminated composite processed by accumulative roll bonding
}

\author{
Abstract \\ ULTRAFINE-GRAINED (UFG) materials have been gathering much interest for the last two decades as the \\ materials have extraordinary mechanical properties such as high strength, low temperature \\ superplastisity, and high corrosion resistance. Severe plastic deformation (SPD) is the most widely used \\ method to produce UFG materials. Accumulative roll bonding (ARB) has become one of the most \\ important SPD techniques since it was first introduced by Saito et al.[1] As the same equipment as in \\ conventional rolling is used, ARB is considered to be one of the most promising methods for \\ manufacturing UFG sheet materials.

\section{Keywords} \\ laminated, microstructure, composite, mechanical, processed, accumulative, roll, bonding, properties, \\ aa5005, aa6061

\section{Disciplines} \\ Engineering | Science and Technology Studies

\section{Publication Details} \\ Su, L., Lu, C., Deng, G. \& Tieu, K. (2014). Microstructure and mechanical properties of AA5005/AA6061 \\ laminated composite processed by accumulative roll bonding. Metallurgical and Materials Transactions \\ B: Process Metallurgy and Materials Processing Science, 45 (2), 515-522.
}




\title{
Microstructure and Mechanical Properties of AA5005/AA6061 Laminated Composite Processed by Accumulative Roll Bonding
}

\begin{abstract}
LIHONG SU, CHENG LU, GUANYU DENG, and KIET TIEU
The AA5005/AA6061 laminated composite has been fabricated by the accumulative roll bonding (ARB) using commercial AA5005 and AA6061. In the ARB process, one piece of AA5005 sheet and one piece of AA6061 sheet were stacked together and rolled with a $50 \mathrm{pct}$ reduction without any lubrication. The materials were heated at $473 \mathrm{~K}\left(200{ }^{\circ} \mathrm{C}\right)$ for 10 minutes before each rolling process and were deformed up to four cycles to accumulate an equivalent strain of 3.2 and form an AA5005/AA6061 laminated composite. Mechanical properties and microstructure of the laminated composites were tested. The hardness and tensile strength increased, and the grain size reduced with the number of ARB cycles. Ultrafine grains elongated along the rolling direction were developed during the ARB process. The thicknesses of the grains of both the AA5005 and AA6061 layers were less than $200 \mathrm{~nm}$ after the fourth cycle. The uniform elongation decreased drastically after the first cycle ARB and stayed almost unchanged after further ARB process. The hardness of the AA5005 layer was slightly lower than that of the AA6061 layer. The microstructures from optical microscope and transmission microscope showed that in the AA6061 layer large precipitates in the micron scale and small particles less than $100 \mathrm{~nm}$ were present, whereas in the AA5005 layer there were large scale precipitates, but no small-sized particles.
\end{abstract}

DOI: $10.1007 / \mathrm{s} 11663-013-9869-\mathrm{x}$

(C) The Minerals, Metals \& Materials Society and ASM International 2013

\section{INTRODUCTION}

ULTRAFINE-GRAINED (UFG) materials have been gathering much interest for the last two decades as the materials have extraordinary mechanical properties such as high strength, low temperature superplastisity, and high corrosion resistance. Severe plastic deformation (SPD) is the most widely used method to produce UFG materials. Accumulative roll bonding (ARB) has become one of the most important SPD techniques since it was first introduced by Saito et al. ${ }^{[1]}$ As the same equipment as in conventional rolling is used, ARB is considered to be one of the most promising methods for manufacturing UFG sheet materials. ${ }^{[2-4]}$

ARB process is schematically shown in Figure 1. During ARB, rolling is conducted on two layered sheets which have exactly the same dimensions and have been stacked together beforehand. The rolling process not only provides large plastic deformation but also has an effect of bonding the two layers together. The bonded specimen of each cycle is subjected to undergo cutting, surface degreasing, brushing, and stacking together, to be ready for the next cycle. ${ }^{[1,2,5-7]}$ As the thickness of the

LIHONG SU, PhD Candidate, CHENG LU, Senior Lecturer, and KIET TIEU, Professor, are with the School of Mechanical, Materials and Methatronic Engineering, University of Wollongong, Australia. Contact e-mail: chenglu@uow.edu.au GUANYU DENG, PhD Candidate, is with the School of Mechanical, Materials and Methatronic Engineering, University of Wollongong, and also with the State Key Lab of Rolling and Automation, Northeastern University, Shenyang, P.R. China.

Manuscript submitted January 21, 2013.

Article published online May 24, 2013. specimen remains unchanged during the process, the deformation may occur repeatedly many times. Considerable microstructural refinement occurs as a result of the accumulative high plastic strain during the ARB process. The multilayered materials obtained from ARB are quite different from materials manufactured by other SPD methods such as equal channel angular pressing (ECAP) or high-pressure torsion (HPT) as the materials after ARB are more like a layered composite. The process also allows bonding of two different kinds of materials to occur so that different properties of the two dissimilar materials would combine. Many studies have been carried out in this area. ${ }^{[8-15]} \mathrm{Al} / \mathrm{Cu},{ }^{[8]} \mathrm{Cu} / \mathrm{Ag},{ }^{[9]} \mathrm{Cu} /$ $\mathrm{Zr},{ }^{[9]} \mathrm{Al} / \mathrm{Ni},{ }^{[10]} \mathrm{Al} / \mathrm{Mg},{ }^{[11,12]} \mathrm{Fe} / \mathrm{Cu},{ }^{[13]}$ and some other laminated composites have been produced by ARB.

Aluminum alloys find wide usage in the industry because of its light-weight nature. Aluminum alloys with UFG structure with extraordinary mechanical properties have high potential in the engineering application. High-strength aluminum alloys have been successfully processed by ARB ${ }^{[6,7]}$ Most of the research, though, uses one kind of aluminum alloy as the starting material. As stated by Hausöl et al., ${ }^{[14]}$ different aluminum alloys have different properties and combination of different types of aluminum alloys by ARB could result in materials with combination of the preferential properties of the base materials. Laminated AA1050/AA5754 and AA6014/AA5754 were produced by Hausöl et al ${ }^{[14]}$ by pre-fabricated sandwiches using AA1050 and AA6014 as clad materials and AA5074 as core materials so that the bonding interfaces at each cycle are the same kind of alloy. In general, 6xxx series have benefits such as medium strength, formability, weldability, corrosion 


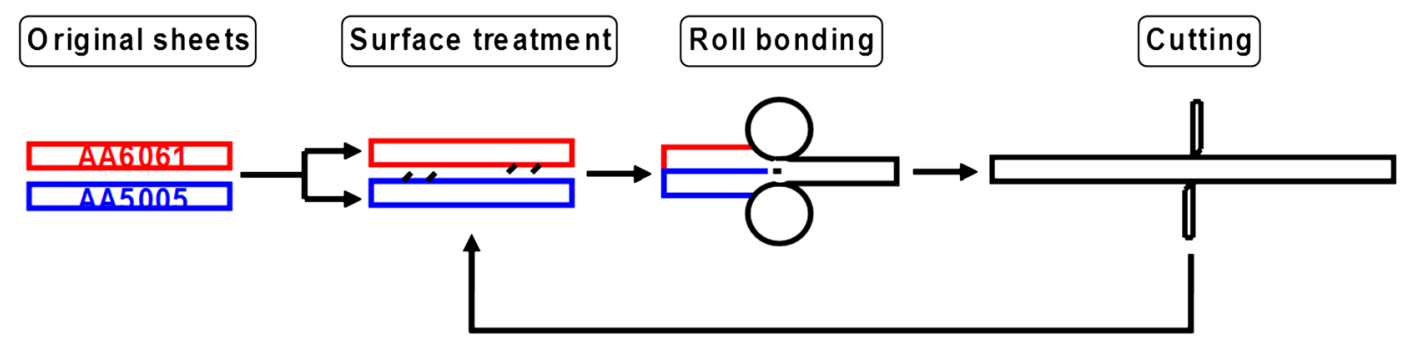

Fig. 1-Schematic illustration of ARB process.

resistance, and low cost. ${ }^{[14]} 5 \mathrm{xxx}$ series aluminum alloys, on the other hand, have been widely used in industry because of their high strength-to-density ratio, good formability, good weldability, and high levels of corrosion resistance. ${ }^{[16]} 5 \mathrm{xxx} / 6 \mathrm{xxx}$ laminated composites would combine the different properties of the two kinds of materials and can be used in applications where $5 \mathrm{xxx}$ or 6xxx aluminum alloys are individually applied. For example, 6xxx series are mostly used for outer panels as car body sheets, while $5 \mathrm{xxx}$ alloys are mostly used for structural panels, ${ }^{[14]} 5 \mathrm{xxx} / 6 \mathrm{xxx}$ laminated composites, on the other hand, can be used in both applications.

In the current research, commercial aluminum alloys AA5005 and AA6061 were used as primary materials in the ARB process to produce laminated composite materials. The two different alloys are bonded directly without any sandwich preparation, as shown in Figure 1. As both the pieces are aluminum alloys, the bonding process is easier than the two different materials, such as aluminum and copper. It is expected that the different properties of the two alloys would combine and enhance the mechanical properties of the composites.

\section{EXPERIMENTAL PROCEDURES}

The materials used in the current study were commercial aluminum alloys AA5005 and AA6061 with initial thickness of $1.5 \mathrm{~mm}$. In order to obtain a fully annealed homogeneous microstructure, both the alloys were annealed at $773 \mathrm{~K}\left(500^{\circ} \mathrm{C}\right)$ for 3 hours, resulting in an average grain size of $50 \mu \mathrm{m}$ for AA5005 and $38 \mu \mathrm{m}$ for AA6061. The optical microscope graphs of the annealed AA5005 and AA6061 are shown in Figure 2. Vickers hardness of the AA5005 and AA6061 were 39.3 and 39.8, respectively. The hardness of the starting materials is close to each other so that the volume fraction of each alloy in the composites could keep at the initial ratio as both the materials would deform at similar speed. Before ARB, sheet materials with a dimension of $1.5 \times 50 \times 400 \mathrm{~mm}^{3} \quad$ (thickness $\times$ width $\times$ length) were cut from the original sheets, with the longitudinal direction parallel to the original rolling direction (RD). Before each rolling cycle, the roll was cleaned by acetone and the roll gap and speed were set to the required setting. One side of the sample was cleaned by acetone and wire-brushed. One piece of AA5005 and one piece of AA6061 were then stacked together and welded at one end. The materials were preheated in a furnace at $473 \mathrm{~K}\left(200^{\circ} \mathrm{C}\right)$ for 10 minutes and then rolled with a nominal reduction around 50 pct under dry condition. The rolled samples were cut into two halves and stacked together by the same method as above with AA5005/AA6061 sequence. The above procedure proceeded for four cycles. This preheating temperature was chosen to achieve good hardening and bonding simultaneously. As reported by I. Topic et al., ${ }^{[17]}$ preheating at $503 \mathrm{~K}\left(230{ }^{\circ} \mathrm{C}\right)$ for 4 minutes resulted in a better compromise between good thermal stability and good bonding for AA6016 than with preheating at $453 \mathrm{~K}$ or $523 \mathrm{~K}\left(180{ }^{\circ} \mathrm{C}\right.$ or $\left.250{ }^{\circ} \mathrm{C}\right)$. They also reported that the thermal stability limit for AA6016 was approximately $473 \mathrm{~K}\left(200{ }^{\circ} \mathrm{C}\right)$. In order to achieve good bonding and avoid big lateral cracks without sacrificing too much on the properties of ARB-processed materials, preheating at a lower temperature of $473 \mathrm{~K}\left(200{ }^{\circ} \mathrm{C}\right)$ and a longer time of 10 minutes were used in this experiment.

The microstructure was observed by optical microscopy and transmission electron microscopy (TEM). The optical microstructures were observed with a Leica DMRM microscope, in the longitudinal cross section after grinding and polishing with a Struer's TegraPol-21 polishing machine to obtain an OPS finish. TEM micrographs were obtained with a JEOL $2011 \mathrm{~F}$ microscope operating at $200 \mathrm{kV}$. Thin foils for TEM were prepared by twin-jet electron polishing with an electrolyte of 25 pct nitric acid in methanol at $253 \mathrm{~K}\left(-20^{\circ} \mathrm{C}\right)$. The graphs were taken on the rolling direction-normal direction (RD-ND) plane. Grain size measurements were performed on several pictures measuring 300 grains, and the grain size distribution was calculated. Since the grains have large aspect ratio and the grain size parallel to the RD is too big, only the grain size normal to the RD was measured.

Mechanical properties of the laminated composites were tests by tensile tests and through thickness Vickers hardness tests. Tensile tests were conducted using an Instron 1341 testing machine with an initial strain rate $10^{-3} / \mathrm{s}$ at room temperature. Tensile specimens with 25-mm gauge length and 6-mm gauge width were processed along the RD of the ARB-processed samples. The fracture surfaces after tensile failure were observed by a JEOL 6490 scanning electron microscope. Vickers microhardness was measured on the RD-ND plane using a Leco hardness testing machine by applying a load of $25 \mathrm{~g}$ for 12 seconds. The hardness was taken along the thickness direction (TD) with $50-\mu \mathrm{m}$ distance of two adjacent indents. Mean hardness values of the AA5005 and AA6061 layer were obtained from 

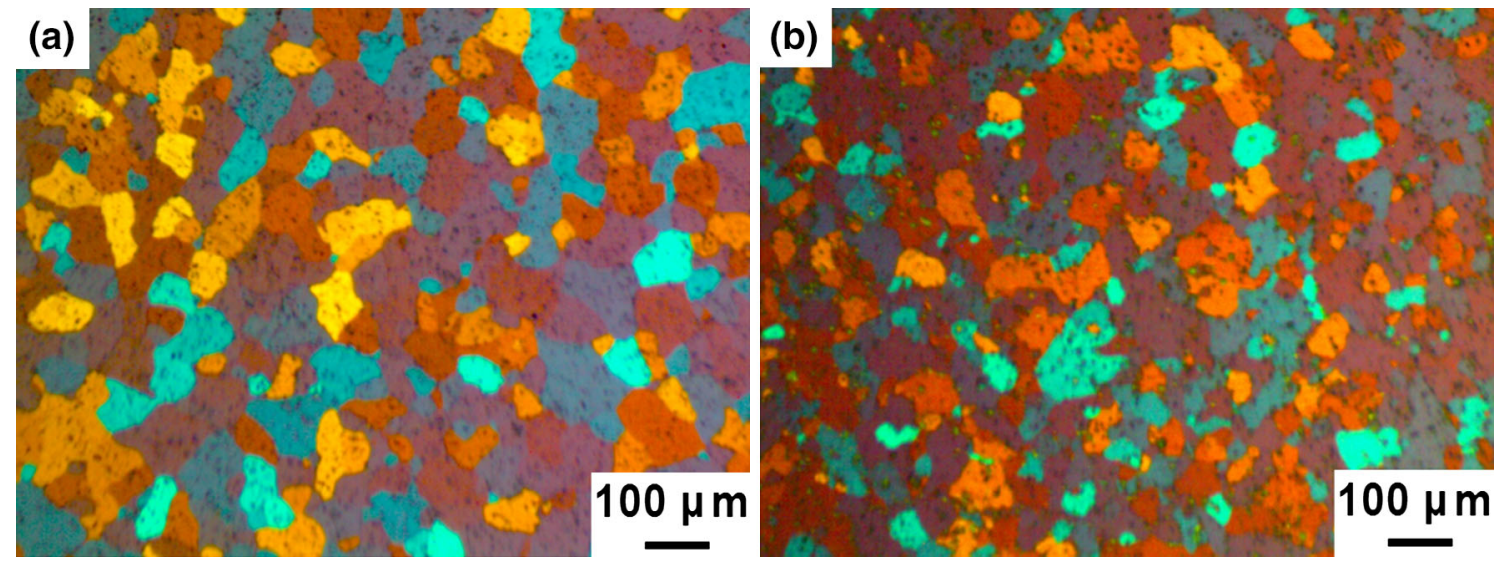

Fig. 2-Optical microscope graphs of (a) AA5005 and (b) AA6061 before ARB.

averaging the indentations within the corresponding alloy layer, regardless of the position of the layer.

\section{RESULTS AND DISCUSSION}

Figure 3 shows the optical microstructures observed at the TD plane of the specimens produced by four-cycle ARB. Good bonding with no delamination between the sheets was attained. As can be seen in Figure 3(a), most of the interfaces are not visible except for the center interface, which is the last formed interface during the process. This means that the bonding of the sheets is formed after a single cycle ARB and further enhanced during the following cycles. The thickness of two different alloy layers is basically the same, as can be seen from some of the interfaces marked in Figure 3(a). The slight difference of the thickness of the samples is due to the slight variation in reduction during rolling and the loss of materials through wire brushing during the surface treatment. As described previously, the hardness of the two starting materials is close to each other, so that the deformation rate of the two alloys is similar, which is different from that of AA1050/AA6061 composites, where because AA1050 is much softer than AA6061, the deformation rates of the two alloys are different so that the AA6061 layer ends up being thicker than the AA1050 layer. $^{[15]}$ It can be seen from Figure 6(a) that both the AA5005 and the AA6061 layers showed dense microsized precipitates. AA6061 and AA5005 layers can be identified by the different morphologies of the precipitates of the two layers. Figure 3(b) is a zoom of the center area of Figure 3(a), and it shows that, at higher magnification, the AA6061 layers show dense precipitates of $\mathrm{Mg}_{2} \mathrm{Si}$ - and Fe-rich precipitates, whereas the AA5005 layers are full of script-like Fe-rich precipitates.

Figure 3(c) indicates two types of interfacial structures in ARB-processed AA5005/AA6061 composites. During ARB, bonding occurs by fracture of the oxide layers to allow the fresh metals to contact each other, which leads to two kinds of areas along the interface. Type I is in direct contact of fresh metals (AA5005/
AA6061 contact in this case), while type II are original metal surfaces with oxide film and other contamination in between. The microstructure of both metal layers close to the Type I interface is similar to the rest of the metal matrix, whereas that of the Type II interface is more refined than the rest of the materials. Detailed description of the two types of interfaces and their formation are given in Reference 18.

Figure 4 shows the optical microstructures of 1, 2, and 4-cycle ARB-processed AA5005/AA6061 composites after etching with Barker's reagent. The optical micrographs were taken on the RD-ND plane close to the thickness center. It can be seen in Figure 4 that the grains after 1-cycle ARB are slightly elongated along the $\mathrm{RD}$, and the grain sizes of both AA5005 and AA6061 are smaller than the original size shown in Figure 2. The grains after 2- and 4-cycle ARB are strongly elongated along the $\mathrm{RD}$, and the grain thickness decreases drastically compared with the initial microstructure. The grain thicknesses of AA5005 and AA6061 layers are closer to each other.

In general, as the ARB processing proceeds, the grain size decreases, while the volume fraction of grain boundaries increases; besides, the fraction of high angle grain boundaries also increases. The grain refinement mechanism includes subgrain formation, grain subdivision and transformation of low angle grain boundaries into high angle grain boundaries. The grain boundaries formed in the rolling process tend to align in the rolling plane and eventually form a banded microstructure which is elongated along the RD and has a large aspect ratio. ${ }^{[19]}$

TEM microstructures observed at the RD-ND plane of the specimens processed by 4-cycle ARB are shown in Figure 5. It is apparent from Figures 5(a) and (b) that the microstructures of both the AA5005 layer and the AA6061 layer are composed of strongly elongated grains with a band structure. The longitudinal direction of the grains lies parallel to the RD. The microstructures of the both the alloys have a typical severe rolling structure with large aspect ratio. It can be seen that the lamellar grain boundaries parallel to the RDs are high angle grain boundaries or at least well-evolved grain boundaries, whereas the boundaries parallel to the 


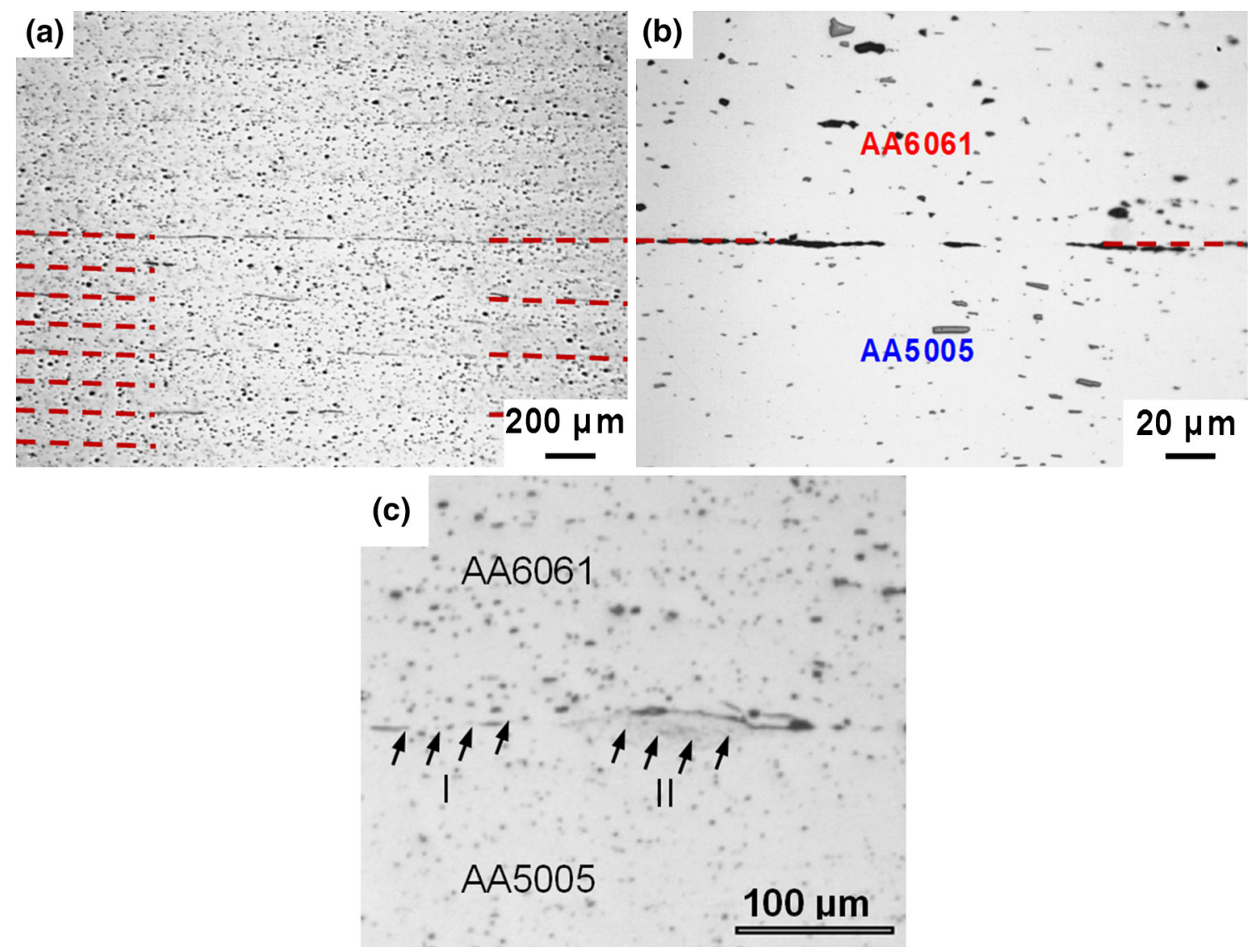

Fig. 3- Optical microscope graphs of the 4-cycle ARB-processed AA5005/AA6061 composite.
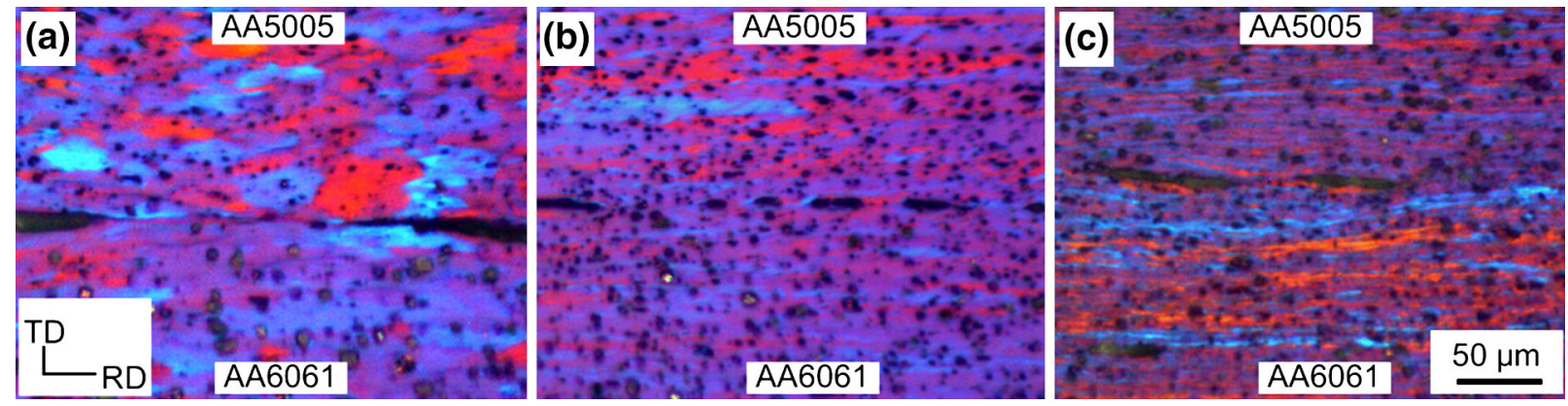

Fig. 4 - Optical micrographs of (a) 1, (b) 2, and (c) 4-cycle ARB-processed AA5005/AA6061 composites.

normal direction (ND) are low angle grain boundaries or interconnecting dislocation cells, as marked by arrows in Figure 5(a). This is in accordance with other reports which state that the grain boundaries in the RD are high angle boundaries and the ones perpendicular to the RD are low angle boundaries, respectively. ${ }^{[5]}$

The gain width distributions are shown in Figures 5(c) and (d). The average band widths of the AA5005 and the AA6061 layer are $138 \mathrm{~nm}$ and $156 \mathrm{~nm}$, respectively. It shows that considerable grain refinement has been achieved during the ARB process. The grain sizes of both the alloys have decreased from tens of microns to less than $200 \mathrm{~nm}$. The grain refinement from the initial materials to the fourth cycle ARB is dramatic and in good agreement with the strength and hardness increase. Although other hardening mechanisms such as precipitation hardening might have effects in this experiment, grain boundary hardening via the Hall-Petch relationship is the major strengthening mechanism. It has also been reported by other researchers that the strength of the ARB-processed aluminum alloys is determined primarily by the UFG structure. ${ }^{[20]}$ TEM graphs show that there exist fine precipitates in the AA6061 layer, of about 50 through $150 \mathrm{~nm}$ in diameter, 

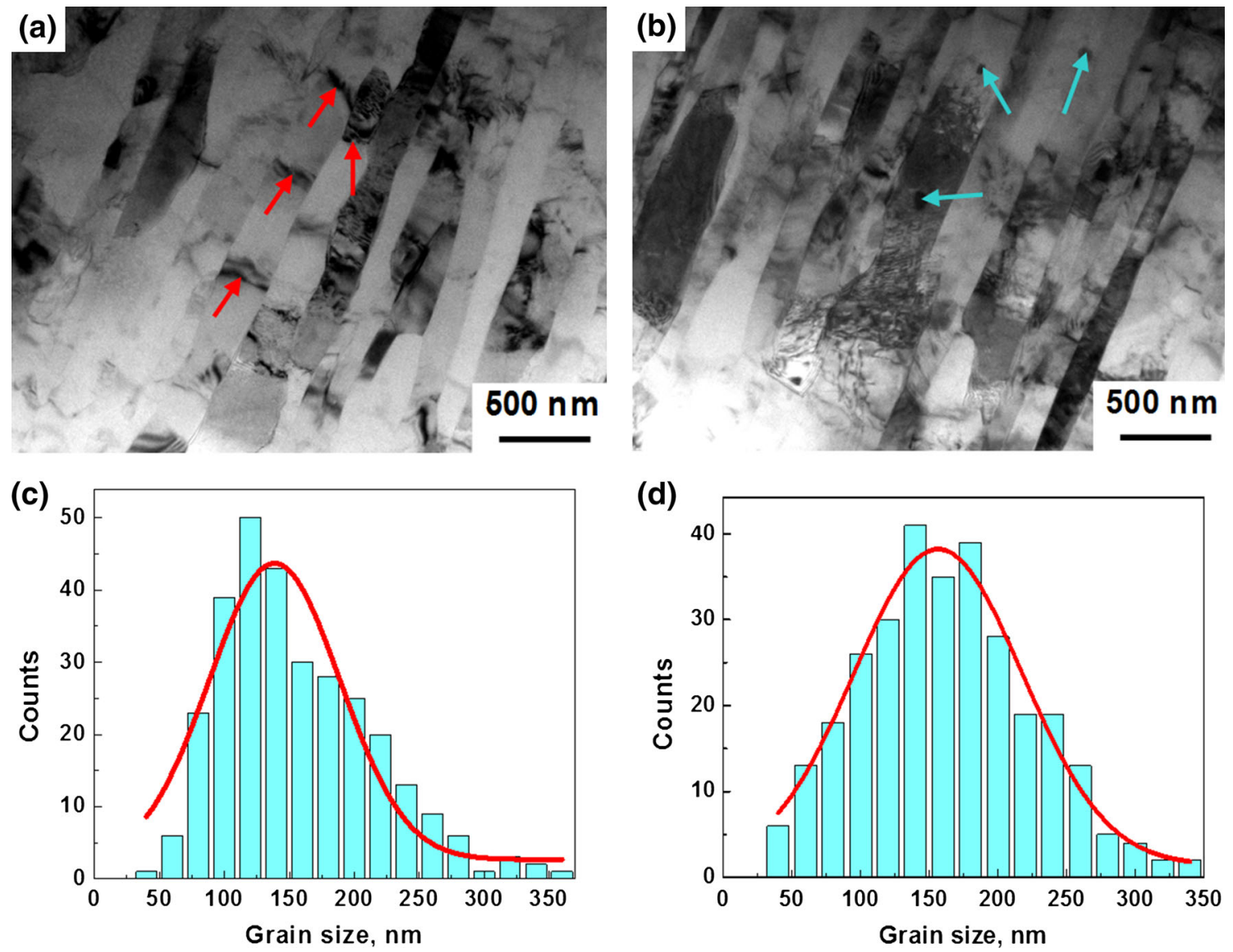

Fig. 5-TEM microstructures of (a) AA5005 layer (b) AA6061 layer and grain size distribution of (c) AA5005 layer, and (d) AA6061 layer after 4-cycle ARB.

as indicated by arrows in Figure 5(b). The AA5005 layer, however, does not show any fine precipitates in this experimental condition. The fine precipitates in the AA6061 layer might behave as obstacles to dislocation movements, and so it may be one of the reasons of higher hardness in this layer.

Tensile results of AA5005/AA6061 composites after 1 through 4-cycle ARB deformations are shown in Figure 6. The engineering stress-strain curves (Figure 6(a)) show that the stress increases and the elongation decreases after ARB deformation. The average values of ultimate tensile strength (UTS) and uniform elongation of the initial materials and ARB-processed AA5005/AA6061 composites are shown in Figure 6(b). The figure shows that after 1-cycle of ARB, the UTS of the composite is about $227 \mathrm{MPa}$, which is about twice the strength of the initial materials before ARB deformation (123 MPa and $134 \mathrm{MPa}$ for AA5005 and AA6061, respectively). The tensile strength increases with the number of ARB cycles and increases up to $334 \mathrm{MPa}$ at the end of 4-cycle ARB, which is about three times the initial value. This indicates that the materials are efficiently strengthened by ARB deformation. The uniform elongation after 1-cycle ARB is about 3 pct, which drops substantially compared with the original materials (over $20 \mathrm{pct}$ ) and then stays at about the same value during the course of further ARB cycles. This phenomenon is the so-called paradox of ductility and strength for nanocrystalline materials and is a typical behavior of soft ductile materials subjected to SPD and has been reported many times. ${ }^{[21,22]}$

Unlike coarse-grained metals, the UFG materials have tensile curves that peak immediately after yielding, which results in low ductility. The high strength and low ductility in tensile tests is the typical behavior of UFG materials. Most of the reported UFG materials are typically several times stronger than their coarse-grained counterparts, but at the same time, the elongation to failure is not more than a few percent. ${ }^{[1,6,7,20]}$ The strain hardening rates of the ARB-processed sheets are higher than the original, annealed material at low true strain, but it decreases rapidly at the very early stage (Figure 6(c)). For the initial annealed materials, on the other hand, the strain hardening rate remains at a relatively higher value even at a strain of as high as 20 pct. The rapid decrement in the strain hardening rate in the ARB-processed sheets is responsible for the early deformation instability and early fracture.

As the two kinds of alloys are distributed as layers next to each other in the composite, the properties of the composite are not uniform throughout the sample. During the tensile tests, the composite is considered as 


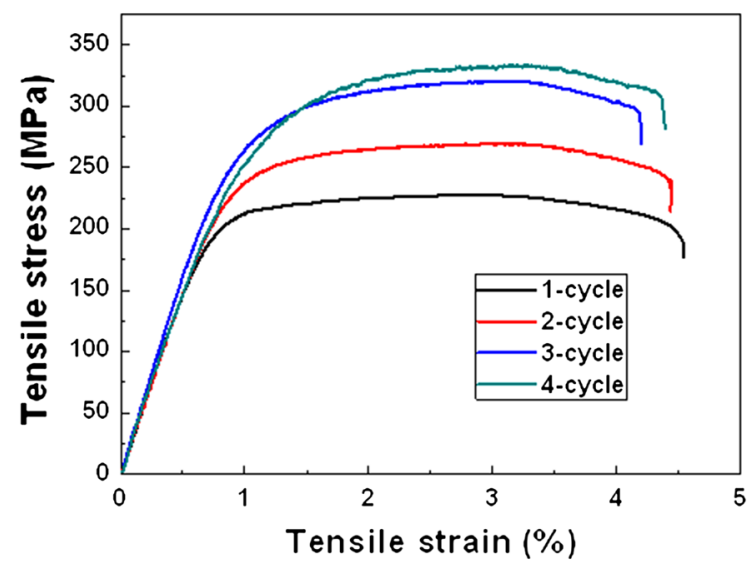

(a)

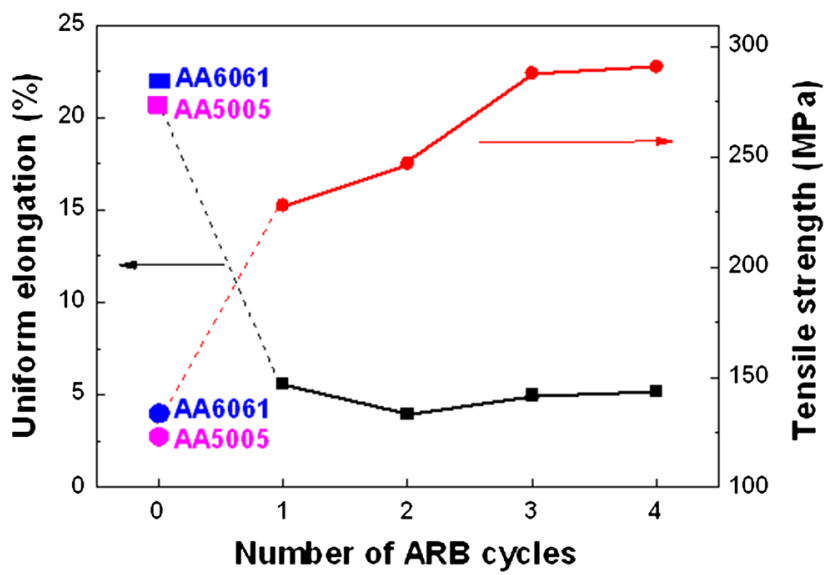

(b)

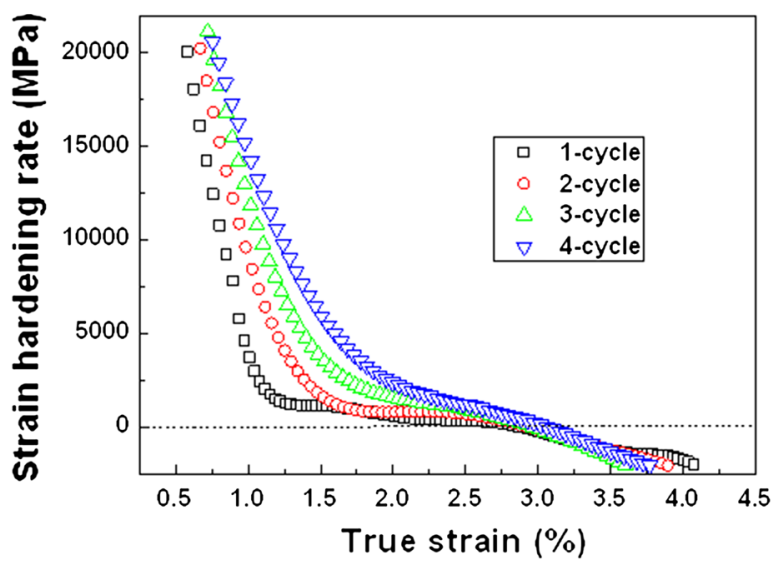

(c)

Fig. 6 - (a) Engineering stress-strain curves, (b) tensile strength and uniform elongation, and $(c)$ strain hardening rates of 1 through 4-cycle ARB-processed AA5005/AA6061 composites.

one piece, and the tensile properties are the combination of the two alloys. To investigate the mechanical properties of each layer, Vickers hardness throughout the thickness of the cross section of the composites are measured. Figure 7 shows the through-thickness hardness distribution of the 1 through 4-cycle ARB-processed composites. It can be seen in Figure 7 that the hardness is not homogeneous in the TD even if only one specific alloy is considered. It shows higher values near the surface and close to interfaces. This behavior had previously been observed and was explained as being due to the redundant shear strain near the surface. ${ }^{[6]}$ The interfaces, which are surfaces in the previous cycle, also gained enormous shear strain. It can be seen in Figure 7(a) that the hardness of AA6061 is generally higher than that of AA5005, but the difference cannot be distinguished easily for the higher cycle ARB-processed composites.

The average hardness values of the AA5005 and AA6061 layers are obtained by averaging the hardness values of the corresponding layers separately. As shown in Figure 8, the hardness values of both the alloys increase steadily with the increasing number of ARB cycles, which trend is similar to the one of the UTS evolution. The hardness of the AA5005 layer is always lower than that of AA6061 layer. It can be seen from the TEM figures shown in Figure 5 that the dislocation density within the interior of the AA5005 layer is lower than that of the AA6061 layer, which is probably one of the reasons that the hardness of the AA6061 layer is higher than that of the AA5005 layer.

The SEM micrographs of the fracture surface of the 4-cycle ARB-processed composite are shown in Figure 9. It shows shear zones and dimples, which are the characteristics of ductile deformation. Most of the interfaces formed after the second cycle ARB can be clearly seen from the fracture surface, which is partly because of the shear zones between the interfaces and partly because of debonding during the tensile process. The interfaces formed in the first cycle ARB are not obvious - some places being even invisible; the two pieces of materials behaved as if they are one. This further proves that the bonding properties can be improved with further ARB cycles. ARB with as many total cycles as possible can be performed to produce composite materials with good bonding. 


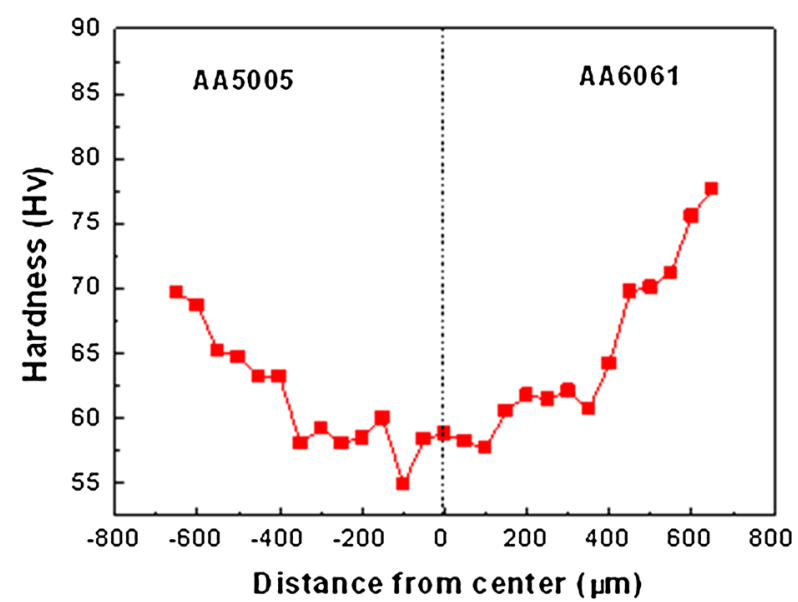

(a)

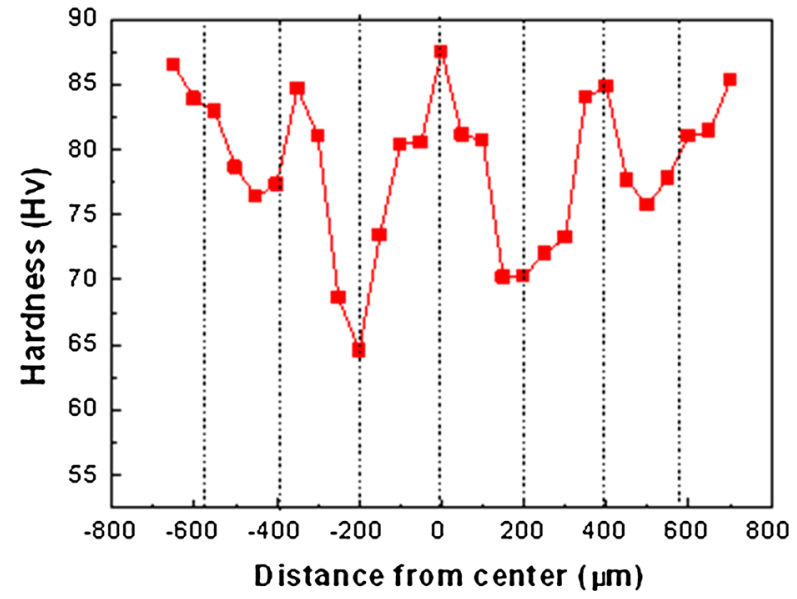

(c)

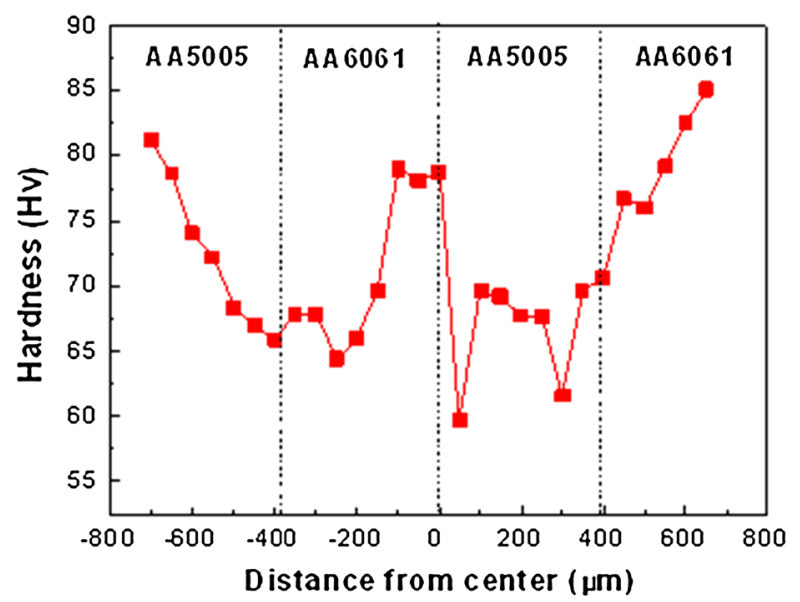

(b)

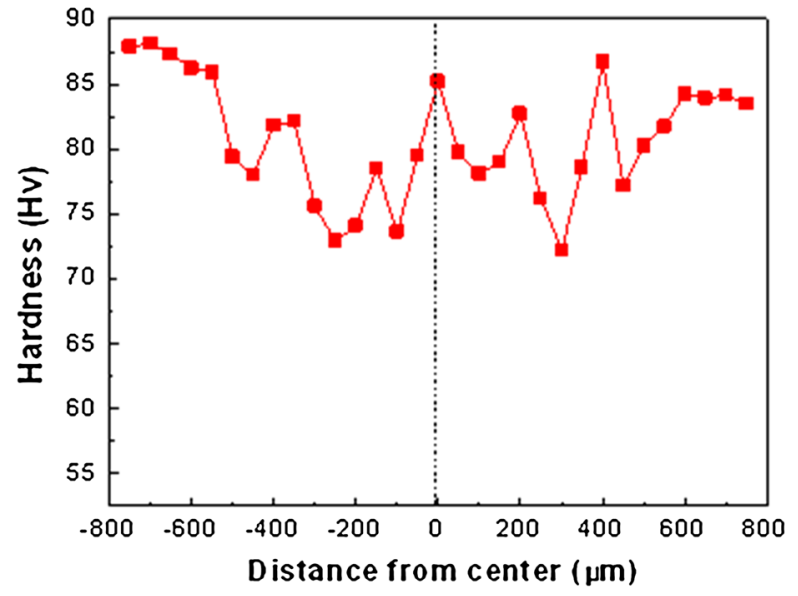

(d)

Fig. 7-Through-thickness hardness distributions of (a) 1-, (b) 2-, (c) 3-, and (d) 4-cycle ARB-processed AA5005/AA6061 composites.

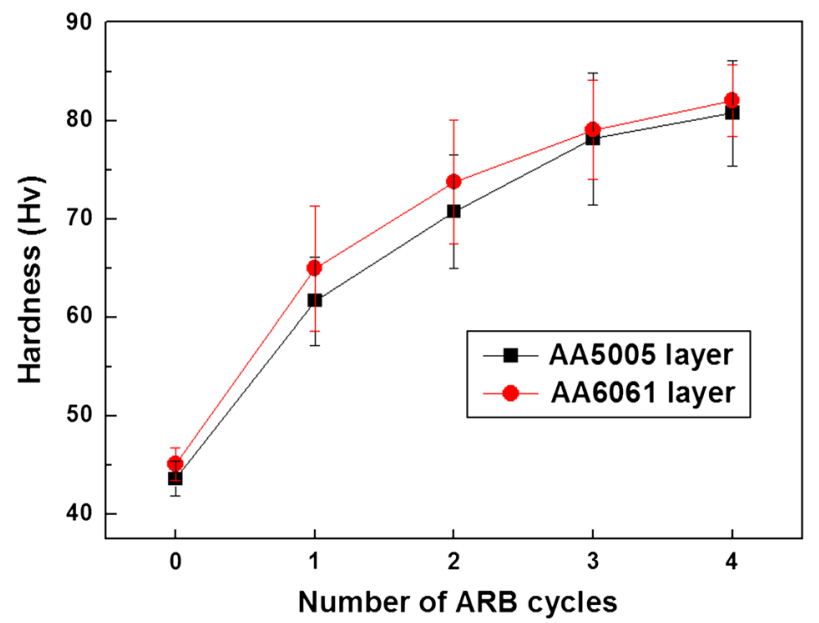

Fig. 8-Average hardness of AA5005 and AA6061 layers after 1 to 4-cycle ARB.

\section{CONCLUSIONS}

The AA5005/AA6061 laminated composite has been successfully fabricated by ARB using dissimilar starting

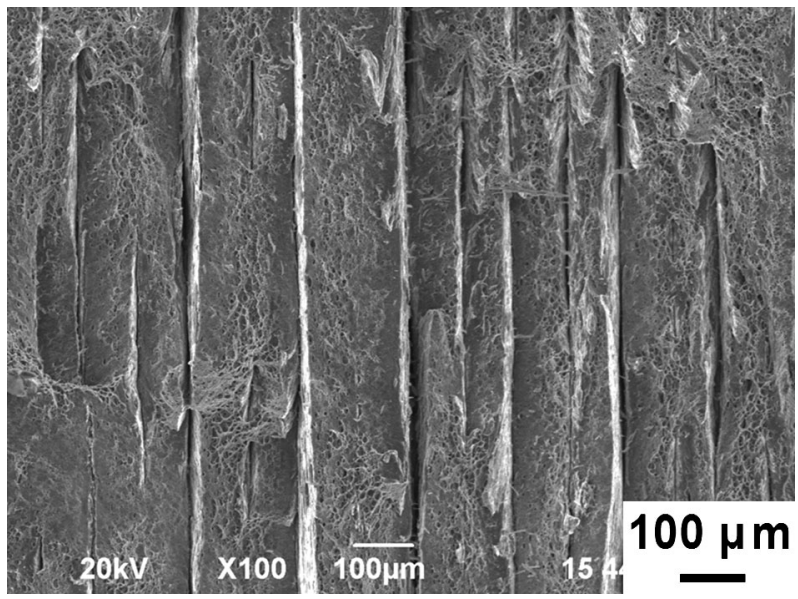

Fig. 9-Fracture surface of 4-cycle ARB-processed AA5005/AA6061 composite.

materials: AA5005 and AA6061. Significant grain refinement has been achieved after 4-cycle ARB. UFG elongated along the RD with the grain thicknesses of 
both the AA5005 and the AA6061 layers being less than $200 \mathrm{~nm}$ have been obtained after the fourth cycle ARB. The hardness and tensile strength increase with the number of ARB cycles to more than twice the initial values, whereas the uniform elongation decreases drastically after the first cycle ARB and stays almost unchanged after further ARB process. The hardness of the AA5005 layer is slightly lower than that of the AA6061 layer which is probably due to the higher interior dislocation density and small-sized precipitates inside the microstructure of AA6061 layer.

\section{ACKNOWLEDGMENTS}

The author would like to thank Mr. Joe Abbott for the help of ARB experiments.

\section{REFERENCES}

1. Y. Saito, N. Tsuji, H. Utsunomiya, T. Sakai, and R.G. Hong: Scripta Mater., 1998, vol. 39, pp. 1221-27.

2. Y. Saito, H. Utsunomiya, N. Tsuji, and T. Sakai: Acta Mater., 1999, vol. 47, pp. 579-83.

3. M.Y. Zhan, Y.Y. Li, W.P. Chen, and W.D. Chen: J. Mater. Sci., 2007, vol. 42, pp. 9256-561.

4. R. Zhang and V.L. Acoff: Mater. Sci. Eng. A, 2007, vol. 463, pp. $67-73$
5. N. Tsuji, Y. Saito, S.H. Lee, and Y. Minamino: Adv. Eng. Mater., 2003, vol. 5, pp. 338-44.

6. S.H. Lee, Y. Saito, T. Sakai, and H. Utsunomiya: Mater. Sci. Eng. A, 2002, vol. 325, pp. 228-35.

7. C. Lu, K. Tieu, and D. Wexler: J. Mater. Process. Technol., 2009, vol. 209, pp. 4830-34

8. M. Eizadjou, A.K. Talachi, H.D. Manesh, H.S. Shahabi, and K. Janghorban: Compos. Sci. Technol., 2008, vol. 68, pp. 2003-09.

9. S. Ohsaki, S. Kato, N. Tsuji, T. Ohkubo, and K. Hono: Acta Mater., 2007, vol. 55, pp. 2885-95.

10. G. Min, J. Lee, S. Kang, and H. Kim: Mater. Lett., 2006, vol. 60, pp. $3255-59$.

11. M.C. Chen, H.C. Hsieh, and W. Wu: J. Alloy Compd., 2006, vol. 416, pp. 169-72.

12. K. Wu, H. Changa, E. Maawad, W.M. Gan, H.G. Brokmeier, and M.Y. Zheng: Mater. Sci. Eng. A, 2010, vol. 527, pp. 3073-78.

13. F.H. Kavarana, K.S. Ravichandran, and S.S. Sahay: Scripta Mater., 2000, vol. 42, pp. 947-54.

14. T. Hausöl, H.W. Höppel, and M. Göken: J. Mater. Sci., 2010, vol. 45 , pp. $4733-38$.

15. L.H. Su, C. Lu, G.Y. Deng, K. Tieu and X.D. Sun: Rev. Adv. Mater. Sci., 2013, vol. 33, pp. 33-37.

16. Y.M. Zhao, W.C. Liu, and J.G. Morris: Metall. Mater. Trans. A, 2004, vol. 35A, pp. 3613-29.

17. I. Topic, H.W. Höppel, and M. Göken: Int. J. Mater. Res., 2007, vol. 98 , pp. $320-24$

18. L.H. Su, C. Lu, A.K. Tieu, and G.Y. Deng: Mater. Sci. Eng. A, 2013, vol. 559, pp. 345-51.

19. F.J. Humphreys, P.B. Prangnell, J.R. Bowen, A. Gholinia, and C. Harris: Philos. Trans. R. Soc. Lond. A, 1999, vol. 357, pp. 1663-80.

20. H. Kim, S. Kang, N. Tsuji, and Y. Minamino: Acta Mater., 2005, vol. 53 , pp. $1737-49$.

21. R.Z. Valiev: Nat. Mater., 2004, vol. 3, pp. 511-16.

22. H.W. Höppel, J. May, and M. Göken: Adv. Eng. Mater., 2004, vol. 6 , pp. $781-84$. 